\title{
Exogenous labile $C$ application enhances Fe-P utilization for mycorrhizal plants through iron-reducing bacteria in subtropical soil
}

\author{
X. Ding ${ }^{1,2}$, S. Zhang ${ }^{1 *}$, R.Wang ${ }^{2}$, X. Liao $^{2}, \mathrm{~S} \mathrm{Li}^{2}$ \\ ${ }^{1}$ College of Resources and Environmental Science, Qingdao Agricultural University, No. 700, Greatwall Road, \\ Chengyang District, Qingdao 266109, China.Corresponding author: zhang_shirong@126.com. \\ ${ }^{2}$ Guangdong Public Lab of Environmental Science and Technology, Guangdong Institute of Eco-Environmental \\ and Soil Sciences, Guangzhou 510650, China.
}

\begin{abstract}
In a greenhouse experiment, Medicago sativa was grown in iron-rich soil inoculated with arbuscular mycorrhizal fungi (Funelliformis mosseae, FM) and/or iron (Fe) -reducing bacteria (IRB, Klebsiella pneumoniae strain L17) with three exogenous labile $\mathrm{C}$ input forms (no $\mathrm{C}$ source, as a single dose, and as a pulse) at rates of P0 and P5 ( 0 and $5 \mathrm{mg} \mathrm{P}_{2} \mathrm{O}_{5} \mathrm{~kg}^{-1}, \mathrm{KH}_{2} \mathrm{PO}_{4}$ ), which is to understand the role of IRB in enhancing the Fe-P utilization with exogenous labile $\mathrm{C}$ in subtropical soil. The results showed when inoculated with IRB, labile $\mathrm{C}$ as a pulsed input significantly improved the mycorrhiza colonization and hyphal length density, and increased the shoot $\mathrm{P}$ content, microbial biomass $\mathrm{C}$ and glomalin content at $\mathrm{P} 5$ rate; meanwhile, the labile $\mathrm{C}$ input also promoted the $\mathrm{Fe}$ (II) production, when inoculated with IRB, labile $\mathrm{C}$ as a pulsed input increased the $\mathrm{C} / \mathrm{A}$ extractable $\mathrm{Fe}(\mathrm{II})$, oxalateextractable $\mathrm{P}$ and microbial biomass $\mathrm{P}$ content. These facts suggested that application of labile $\mathrm{C}$ as a pulsed input enhanced the ability of IRB in improving the Fe reduction and Fe-P utilization in subtropical soil.
\end{abstract}

Keywords: Mycorrhizal plants; Iron-reducing bacteria (IRB); Labile C input forms; Fe-P; Microbial biomass $\mathrm{C} / \mathrm{P}(\mathrm{MBC} / \mathrm{P})$. 


\section{Introduction}

Phosphorus (P) is necessary for plant growth, but it has become a limited resource. In subtropical soils, $\mathrm{P}$ limitation is likely derived in part from the oxidation of secondary minerals, such as iron (Fe) and aluminum (Al) oxides and hydroxides (Liptzin and Silver 2009), which can bind $\mathrm{P}$ and make it temporarily unavailable for plants and microbes. $\mathrm{Fe}$ is provided with redox dynamics, which significantly affect $\mathrm{P}$ cycling and release (Baldwin and Mitchell 2000). As a large potential $P$ pool, the improving $\mathrm{P}$-use efficiency is necessary by making Fe-P available for plants. Biological process related to $\mathrm{P}$ removal or desorption have attracted increasing attention, such as the application of iron-reducing bacteria (IRB) to reduce Fe(III) from cheap Fe hydroxides (Ivanov et al. 2005). IRB can use $\mathrm{Fe}(\mathrm{III})$ as electron acceptors coupled with the oxidation of organic matter and energy obtained from such reactions can be used for maintenance and growth (Lovley et al. 2004).

In highly weathered, humid subtropical soils, IRB is an ecologically and environmentally important group of microorganisms that significantly affect the decrease in redox potential (Lovley et al. 2004). Plant root exudates provide readily available $\mathrm{C}$ substrates for bacterial growth, therefore producing microbial biomass $\mathrm{P}$ (MBP) in the rhizosphere (Adesemoye Kloepper 2009). Arbuscular mycorrhizal fungi (FM) growth enhances the complex organic material in rhizosphere and hyphosphere soil and thus stimulates the growth of fungi and bacteria with the exudation of FM (Bago et al. 2002). Several soil bacterial isolates can attach to and colonize living and dead FM hyphae (Toljander et al. 2006), which can indirectly reduce the oxidationreduction potential in the mycorrhizosphere. Exploration of the effects of FM and IRB interactions in $\mathrm{P}$ nutrient turnover and plant uptake has therefore been of considerable interest to better understand integrated belowaboveground links and ecosystem functioning (Richardson and Simpson 2011; Minaxi et al. 2013). Therefore, regulating the two processes to increase the bacterial mobilization of $\mathrm{P}$ but reduce its immobilization is the central issue in enhancing Fe-P use efficiency. The concept of the biological transformation or turnover of Fe$\mathrm{P}$ has long been proposed. Fe-P mineralization is driven by mycorrhizal plant and IRB under P-deficient soil conditions or by microbialderived inorganic phosphate to MBP in bulk soil (Richardson and Simpson 2011). However, in our previous studies, soil microbial biomass $\mathrm{C}$ (MBC) at P5 rate is significantly higher than that at $\mathrm{P} 0$ rate in IRB $\times \mathrm{FM}$ treatment (Zhang et al. 2013), suggesting that labile $C$ from the secretions and mycelia of FM hyphae at $\mathrm{P} 0$ rate cannot meet the need for the redox reactions of IRB. The present study aims to investigate the effect of exogenous application of labile $\mathrm{C}$ on soil Fe-P mineralization. We hypothesized that exogenous application of labile $\mathrm{C}$ stimulates the rates of $\mathrm{Fe}$ reduction with IRB for the mineralization and desorption of Fe-P, and available $\mathrm{P}$ is absorbed by FM for plants. The results can provide experimental evidence for understanding the relationship between IRB and FM in humid subtropical soil. 


\section{Materials and Methods}

\subsection{Soil and microcosms}

The soil used in this study was obtained from the Research Farm of Baiyun Agriculture Science Experimental Center $\left(23^{\circ} 16^{\prime} 10^{\prime \prime} \mathrm{N}, 113^{\circ} 18^{\prime} 12^{\prime \prime}\right.$ E), Guangzhou, Guangdong Province, China. This soil was a clay soil with the following physicochemical properties: $\mathrm{pH}$ (soil: $\mathrm{H}_{2} \mathrm{O}=1: 5$ ) 6.0, organic matter $16.05 \mathrm{mg} \cdot \mathrm{kg}^{-1}$, total Fe $21.5 \mathrm{~g}$ $\mathrm{kg}^{-1}$, amorphous Fe $2.10 \mathrm{~g} \mathrm{~kg}^{-1}$, free Fe $7.54 \mathrm{~g} \mathrm{~kg}^{-}$ 1, mineral nitrogen $7.2 \mathrm{mg} \cdot \mathrm{kg}^{-1} \mathrm{NO}_{3}^{-}$and $\mathrm{NH}_{4}^{+}$, analyzed by continuous flow analysis [TRAACS 2000]), Olsen-P [( $\left.\mathrm{NaHCO}_{3}\right)$-extractable] 6.2 $\mathrm{mg} \cdot \mathrm{kg}^{-1}$, and $\mathrm{NH}_{4} \mathrm{Cl}$-exchangeable potassium $87.5 \mathrm{mg} \cdot \mathrm{kg}^{-1}$. The soil was air-dried, sieved (2 $\mathrm{mm}$ ), and then irradiated before use to eliminate indigenous microorganisms $\left(10 \mathrm{kGy}{ }^{60} \mathrm{Co} \gamma\right.$-rays, Beijing Radiation Application Research Center, China).

The microcosms used were acrylic boxes constructed to permit spatial separation of soil zones for root and hyphal growth. The boxes had two compartments, one for root growth, including for the growth of mycorrhiza structures (root compartment, length $\times$ width $\times$ height $=5 \times 10 \times 15 \mathrm{~cm}$ ), and another (buffer zone and hyphal compartment, length $\times$ width $\times$ height $=5 \times 10 \times 15 \mathrm{~cm}$ ) separated by a $30 \mu \mathrm{m}$ nylon mesh through which hyphae but not roots can pass. Soil density was adjusted to $1.2 \mathrm{~g} \cdot \mathrm{cm}^{-}$ 3 and was added to the boxes in the following amounts: $800 \mathrm{~g}$ in the root compartment, 320 $\mathrm{g}$ in the buffer zone, and $480 \mathrm{~g}$ in the hyphal compartment. All microcosms were applied with basal mineral nutrients as follows: 200 mg N (Nitrogen) $\mathrm{kg}^{-1}$ soil (as $\mathrm{NH}_{4} \mathrm{NO}_{3}$ ), 200 mg K (Potassium) $\mathrm{kg}^{-1}$ soil (as $\mathrm{K}_{2} \mathrm{SO}_{4}$ ), $5 \mathrm{mg}$ $\mathrm{Cu}$ (Copper) $\mathrm{kg}^{-1}$ soil (as $\mathrm{CuSO}_{4}$ ), and $5 \mathrm{mg} \mathrm{Zn}$ (Zinc) $\mathrm{kg}^{-1}$ soil (as $\mathrm{ZnSO}_{4}$ ). Soil moisture was kept at $18 \%$ to $20 \%(\mathrm{w} / \mathrm{w}$, about $70 \%$ of water holding capacity) as determined by the weighing of the pots every $2 \mathrm{~d}$ during the experiment.

\subsection{Host plants and mycorrhiza inoculum}

Seeds of alfalfa (Chinese Medicago sativa $\mathrm{L}$. cultivar 'Aohan') were surface-sterilized in a $10 \%(\mathrm{v} / \mathrm{v}) \mathrm{H}_{2} \mathrm{O}_{2}$ solution for $10 \mathrm{~min}$ and in a $70 \%(\mathrm{v} / \mathrm{v})$ ethanol solution for $3 \mathrm{~min}$ and were then thoroughly washed with sterile deionized water. After germination at 26 ${ }^{\circ} \mathrm{C}$ in the dark for $2 \mathrm{~d}, 30$ germinated seeds were sown in each pot and were thinned to 20 seedlings $3 \mathrm{~d}$ after emergence. The arbuscular mycorrhizal fungi inoculum used was Funelliformis mosseae (FM) (Nicol. and Gerd.) Gerdemann and Trappe (BEG 167). FM was obtained by Professor Youshan Wang from the Institute of Plant Nutrition and Soil Science, Beijing Academy of Agriculture and Forestry Sciences, China. The fungal spores were isolated by wet sieving, and 1000 spores were inoculated to the soil of the root compartment before the germinated seeds were sown. The IRB strain (Klebsiella pneumoniae strain L17) was obtained by Professor Shungui Zhou from the Guangdong Institute of Eco-Environmental and Soil Sciences, which can reduce Fe (III) oxides. Cultures were grown in a liquid LB medium under aerobic conditions on a rotary shaker at $180 \mathrm{rev} \mathrm{min}^{-1}$ at $30^{\circ} \mathrm{C}$ and were harvested by centrifugation at $6900 \mathrm{~g}$ at $4{ }^{\circ} \mathrm{C}$ for 10 min when it approached the exponential 
phase. The pellets were washed thrice and resuspended in a sterile fresh basal medium to an optical density of 1.8 to $2.2(\lambda=600 \mathrm{~nm})$. One milliliter of the suspension was added to $25.2 \mathrm{~mL}$ serum bottles containing $19 \mathrm{~mL}$ of the basal medium. Based on the correlation between culture optical density and viable cell counts as determined by serial dilution and plating, a density of 2.2 corresponded to approximately $3 \times 10^{9}$ cells $\mathrm{mL}^{-1}$. On the 3rd and 10th $\mathrm{d}$ after emergence, $10 \mathrm{~mL}$ of bacterial suspension was added to the soil of the inoculated treatments, and $10 \mathrm{~mL}$ of sterilized normal saline was added to the noninoculated treatments as control, respectively.

\subsection{Experimental design}

The experiment consisted of four main treatments comprising two different inoculations, namely, (1) FM and no IRB inoculation (-IRB) or (2) FM and IRB inoculation (+IRB), and two inorganic $\mathrm{P}$ rates, namely, $0(\mathrm{P} 0)$ or $5 \mathrm{mg} \mathrm{P} \mathrm{kg}^{-1}$ soil (P5) as $\mathrm{KH}_{2} \mathrm{PO}_{4}$, and was applied only to the hyphal compartment. Within each main treatment were three sub-treatments: without an additional $\mathrm{C}$ source (-C), $24 \mathrm{mM}$ sodium acetate was added at a rate of $23.04 \mathrm{mg} \mathrm{C}$ as a single dose $(\mathrm{Ci})$, and as a pulse in four installments on days $0,10,17,24$, and 34 to the hyphal compartment (Cp). The experiment was carried out with four-fold replication, and the 48 boxes were arranged in a randomized block design in the greenhouse, with the position of each box re-randomized every week. Distilled water was supplied to all compartments to maintain the soil moisture level close to field capacity (about 20\% w/w) during the growth period.

\subsection{Harvest and sample analysis}

The plants were harvested six weeks after emergence. The rhizoboxes were dismantled and separated into root and hyphal compartments, and the top $2 \mathrm{~cm}$ of soil was removed. The mycorrhiza colonization of roots was measured following the method described by Trouvelot et al. (1986). External mycorrhizal hyphae were extracted from two $5 \mathrm{~g}$ soil samples from the rhizosphosphere soil, using the membrane filter technique (Stadd on et al. 1999). Hyphal length was assessed using the gridline intercept method at $200 \times$ magnification and then convert ed to hyphal length density ( $\mathrm{m} \mathrm{g}^{-1} \mathrm{DW}$ [dry weight] soil ).

Soil acid-extractable $\mathrm{Fe}(\mathrm{II})$ in hyphal compartments was extracted with $0.5 \mathrm{~N} \mathrm{HCl}$ (Chao and Zhou 1983), and ferrozine assay was performed (Lovley and Phillips 1987). Oxalateextractable $\mathrm{Fe}$ and the associated $\mathrm{P}$ pool were extracted with $0.2 \mathrm{M}$ ammonium oxalate at pH 3 in the dark (McKeague and Day 1966). Oxalate extractable P was determined according to Szilas et al. (1998) to avoid interference of the oxalate reagent. A $10 \mathrm{~mL}$ aliquot of extract was combined with $5 \mathrm{~mL}$ concentrated $\mathrm{HNO}_{3}$, evaporated at $100^{\circ} \mathrm{C}$, and digested. The residue was dissolved in $2 \mathrm{~mL}$ of $0.3 \mathrm{M} \mathrm{H}_{2} \mathrm{SO}_{4}$. P was measured using the colorimetric method (Murphy and Riley 1962) after the solution was adjusted to $\mathrm{pH} 4$ with p-nitrophenol. Oxalate extractable Fe was measured on an inductively coupled plasma spectrophotometer. A second soil subsample was extracted in $0.10 \mathrm{~N} \mathrm{NaOH}$ 
and analyzed for $\mathrm{P}$ according to Murphy and Riley (1962).

Soil MBC and MBP in hyphal compartments were determined as in Brookes et al. (1985) and Vance et al. (1987). Before biological analyses, the soils were incubated (50\% water holding capacity) at $25{ }^{\circ} \mathrm{C}$ in half-light for $7 \mathrm{~d}$. Then, $10 \mathrm{~g}$ of a fresh soil sample was fumigated with ethanol-free chloroform at $25{ }^{\circ} \mathrm{C}$ in an evacuated extractor for $24 \mathrm{~h}$. Fumigated and non-fumigated soils were extracted with 40 $\mathrm{mL} \quad 0.5 \mathrm{M} \mathrm{K}_{2} \mathrm{SO}_{4}$ (soil/extractant=1:4) and were shaken for $1 \mathrm{~h}$ on a reciprocal shaker to extract microbial $\mathrm{C}$ and $\mathrm{P}$ from the lysed microorganisms. Organic $\mathrm{C}$ in the extract was measured by $\mathrm{K}_{2} \mathrm{Cr}_{2} \mathrm{O}_{7}$ colorimetric oxidization as described by the Walkley-Black method (1947). At the same time, the soil extracts were analyzed for microbial $\mathrm{P}$ (Amato and Ladd 1988). All data are expressed on an ovendried $\left(105{ }^{\circ} \mathrm{C}\right)$ soil weight basis. MBC was calculated as microbial $\mathrm{C}(\mathrm{mg}) \mathrm{E}_{\mathrm{C}} / \mathrm{K}_{\mathrm{EC}}$, where $\mathrm{EC}$ is the organic $\mathrm{C}$ extracted from fumigated soils minus the organic $\mathrm{C}$ extracted from nonfumigated soils, and $\mathrm{K}_{\mathrm{EC}}$ is 0.35 and represents the fraction of the eliminated biomass extracted as $\mathrm{C}$ under standardized conditions (Sparling et al. 1990). Soil total glomalin in hyphal compartments was determined as described by Wright and Updahyaya (1998). Concentrations of glomalin were extrapolated to $\mathrm{mg} / \mathrm{g}$ for the dry weight.

\subsection{Data analysis}

A test of Normality and Bartlett's test for homogeneity of variance were conducted by PROC UNIVARIATE using the SAS TM software (SAS Institute Inc. 1989) to confirm that all data were normally distributed and the variances were homogenous. Data on all parameter/response variables (e.g., AMF colonization, hyphal length density, shoot and root $\mathrm{P}$ contents, soil MBC, soil glomalin, etc.) were subjected to a two-way ANOVA. Fisher's least-significant-difference test was used to test for significant differences between treatment means at the 5\% level.

\section{Results}

The plant dry weights values of two-way ANOVA analyses results are shown in Table 1. They indicated the effects of label $\mathrm{C}$ input, IRB inoculation and their interactions on the determined variables.

\subsection{Mycorrhiza colonization and hyphal length density}

The root colonization and hyphal length density among three kinds of label $\mathrm{C}$ input had no differences for mycorrhizal plants inoculated without IRB or with IRB at P0 rate and without IRB at P5 rate (Table 1). Compared with inoculation without IRB, IRB inoculation 
significantly increased root colonization at the same labile $\mathrm{C}$ level at both $\mathrm{P}$ rate and hyphal length density at the same labile $\mathrm{C}$ level at P5 rate. Labile $\mathrm{C}$ added as a pulsed input had higher root colonization and hyphal length density than other labile $\mathrm{C}$ treatment for IRB inoculation at the P5 rate.

Table 1. Effect of labile $\mathrm{C}$ source on shoot and root dry weight of mycorrhizal plants inoculated without IRB (-IRB) and with IRB (+IRB) at P0 and P5. +IRB is the soil with

\begin{tabular}{|c|c|c|c|c|c|}
\hline \multirow{2}{*}{ Inoculation } & \multirow{2}{*}{ Labile C levels } & \multicolumn{2}{|c|}{ Root colonization rate $(\%)$} & \multicolumn{2}{|c|}{ Hyphal length density $\left(\mathrm{m} \mathrm{g}^{-1}\right)$} \\
\hline & & $\mathrm{P} 0$ & P5 & $\mathrm{P} 0$ & P5 \\
\hline \multirow{3}{*}{$-\mathrm{IRB}$} & $-\mathrm{C}$ & $35 \pm 7 a^{1} B^{4}$ & $41 \pm 9 \mathrm{a} A$ & $1.2 \pm 0.2 \mathrm{a} A$ & $1.9 \pm 0.3 \mathrm{a} B$ \\
\hline & $\mathrm{Ci}$ & $36 \pm 6 \mathrm{a} B$ & $43 \pm 5 \mathrm{a} B$ & $1.2 \pm 0.3 \mathrm{a} A$ & $1.8 \pm 0.4 \mathrm{a} B$ \\
\hline & $\mathrm{Cp}$ & $44 \pm 8 \mathrm{a} B$ & $46 \pm 12 \mathrm{a} B$ & $1.5 \pm 0.4 \mathrm{a} A$ & $2.1 \pm 0.4 \mathrm{a} B$ \\
\hline \multicolumn{2}{|c|}{ Mean $^{2}$} & $40 \pm 7 \mathrm{~B}^{3}$ & $44 \pm 10 \mathrm{~B}$ & $1.3 \pm 0.4 \mathrm{~A}$ & $2.0 \pm 0.3 \mathrm{~B}$ \\
\hline \multirow{4}{*}{$+\mathrm{IRB}$} & $-\mathrm{C}$ & $56 \pm 6 \mathrm{a} A$ & $46 \pm 6 \mathrm{~b} A$ & $1.5 \pm 0.4 \mathrm{a} A$ & $2.5 \pm 0.3 \mathrm{~b} A$ \\
\hline & $\mathrm{Ci}$ & $53 \pm 9 \mathrm{a} A$ & $55 \pm 5 \mathrm{~b} A$ & $1.4 \pm 0.6 \mathrm{a} A$ & $2.7 \pm 0.4 \mathrm{~b} A$ \\
\hline & $\mathrm{Cp}$ & $57 \pm 8 \mathrm{a} A$ & $84 \pm 11 \mathrm{a} A$ & $1.8 \pm 0.5 \mathrm{a} A$ & $3.6 \pm 0.5 \mathrm{a} A$ \\
\hline & Mean & $57 \pm 8 \mathrm{~A}$ & $61 \pm 11 \mathrm{~A}$ & $1.6 \pm 0.4 \mathrm{~A}$ & $2.9 \pm 0.4 \mathrm{~A}$ \\
\hline \multicolumn{6}{|c|}{ ANOVA (F values) } \\
\hline & 3 level & $13.46^{*}$ & $15.18 * *$ & $11.12^{\mathrm{NS}}$ & $18.15^{*}$ \\
\hline Labile & C level (C) & $18.68^{\mathrm{NS}}$ & $24.37^{*}$ & $23.68^{\mathrm{NS}}$ & $15.42^{\mathrm{NS}}$ \\
\hline & $\mathrm{B} \times \mathrm{C}$ & $14.34 * *$ & $13.21 *$ & $14.26^{\mathrm{NS}}$ & $11.14 * *$ \\
\hline
\end{tabular}

Notes: Data are the means of four replicates \pm SEs. * denotes significant difference at $P=0.05$, ** denotes significant difference at $P=0.01$, and NS denotes no significant difference. Data represent $\mathrm{F}$ values. ${ }^{1}$ Within each column, values with different letters are significantly different at the $P=0.05$ level. Across alllabile $\mathrm{C}$ levels. ${ }^{2}$ Mean value for IRB level. ${ }^{3}$ Mean values with different capital letters are significantly different at the $P=0.05$ level between IRB levels. ${ }^{4}$ Values marked with different italic capital letters represent significant difference at the $P=0.05$ level between $-\mathrm{IRB}$ and $+\mathrm{IRB}$ at a given $\mathrm{P}$ rate.

\subsection{Plant P content}

At $\mathrm{P} 0$ rate with IRB inoculation (+IRB), the shoot $\mathrm{P}$ content of labile $\mathrm{C}$ added as a pulse was greater than that of other labile $\mathrm{C}$, which had no difference. However, at P5 rate with IRB inoculation (+IRB), the shoot $\mathrm{P}$ content of labile $\mathrm{C}$ added as a pulsed input $>$ labile $\mathrm{C}$ added as a single dose $>$ without labile $\mathrm{C}$ input (Figure 1). For the root $\mathrm{P}$ content, no difference was found among three kinds of labile $\mathrm{C}$ input forms at the same $\mathrm{P}$ rate whether with or without IRB inoculation, except that labile $\mathrm{C}$ added as a pulsed input increased root $\mathrm{P}$ content with IRB inoculation at P5 rate. Compared without IRB inoculation, IRB inoculation significantly increased plant P content at P5 rate (Figure 1). These results suggest a significant interaction between labile $\mathrm{C}$ as a pulsed input and inoculation with IRB for plant $\mathrm{P}$ content. 


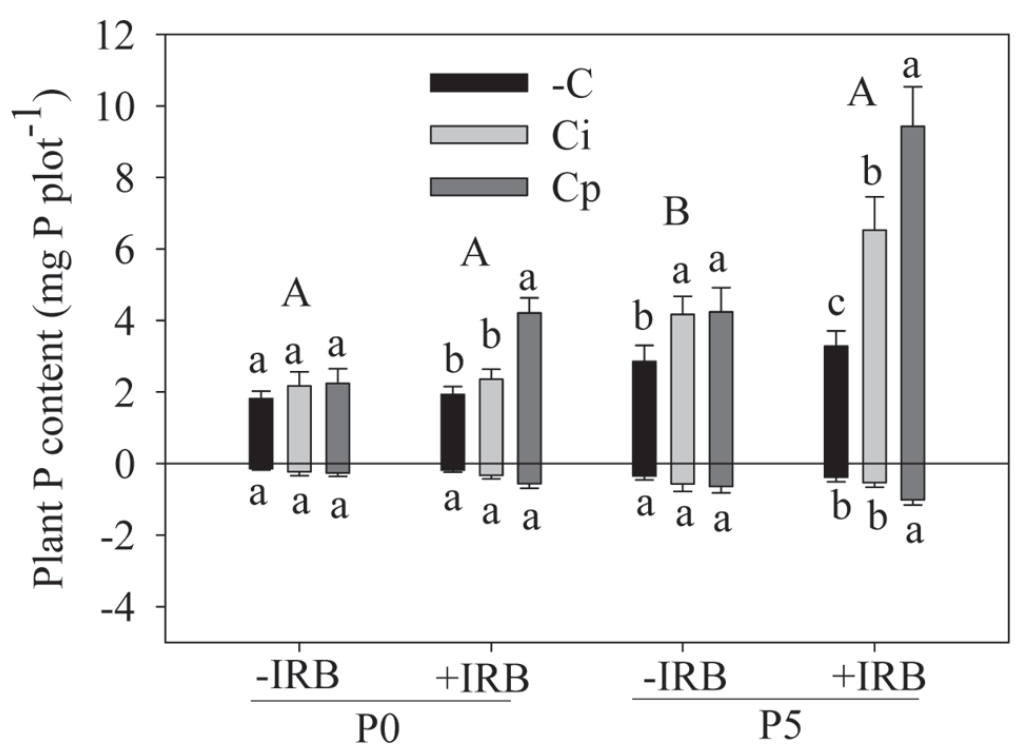

Figure 1. Effect of labile $\mathrm{C}$ source on $\mathrm{P}$ content of shoots (above zero lines) and roots (below zero lines) for mycorrhizal plants inoculated without IRB (-IRB) and with IRB (+IRB) at P0 and P5. Different lowercases above/below the columns indicate significant difference $(\mathrm{P}<0.05)$ of $\mathrm{P}$ content among three labile $\mathrm{C}$ sources. Different uppercases indicate significant difference $(\mathrm{P}<0.05)$ of plant $P$ content between $-I R B$ and + IRB inoculations at the same P rate. Bars represent mean + SE $(n=4)$.

\subsection{Soil P content}

Alkali-extractable $\mathrm{P}$ content had no changes among the three labile $\mathrm{C}$ input forms (Figure 2a). Oxalate-extractable P content with IRB inoculation was significantly higher than that without IRB inoculation whether at P0 or $\mathrm{P} 5$ rate. At $\mathrm{P} 5$ rate, oxalate-extractable $\mathrm{P}$ content increased with labile $\mathrm{C}$ input with IRB inoculation, where labile $\mathrm{C}$ added as a pulsed input was greater than labile $\mathrm{C}$ added as a single dose, as well as the no labile $\mathrm{C}$ input (Figure 2b).
IRB inoculation increased soil MBP content compared without IRB inoculation whether at $\mathrm{P} 0$ or P5 rate $(P<0.001$; Figure $2 \mathrm{c})$. The increment content was relevant to the labile $\mathrm{C}$ input forms and $\mathrm{P}$ rate. The soil MBP content in labile $\mathrm{C}$ added as a single dose treatment with IRB inoculation brought about a twofold increase over that without IRB inoculation $(P<0.001)$. Moreover, the labile $\mathrm{C}$ added as a pulsed input treatment with IRB inoculation showed a threefold increase in soil MBP content compared with non-inoculation $(P<0.001)$. A significant relationship between MBP and IRB ( $P=0.001)$ suggested that IRB inoculation effects differed among labile $\mathrm{C}$ input forms. 

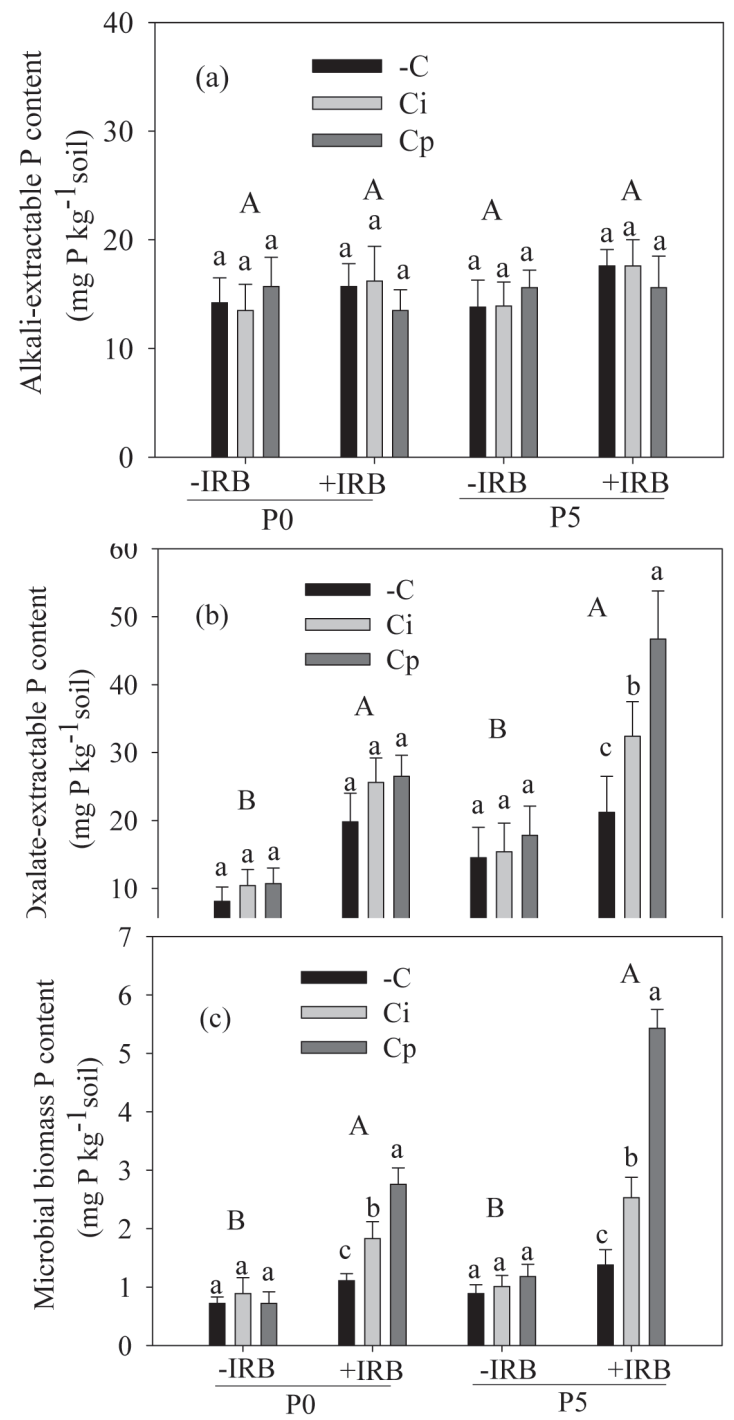

Figure 2. Effect of labile $C$ source on alkali-extractable $P(a)$, oxalate-extractable $P(b)$, and microbial biomass $\mathrm{P}$ (MBP) content (c) in hyphosphere soil of mycorrhizal plants inoculated without IRB (-IRB) and with IRB $(+\mathrm{IRB})$ at $\mathrm{P} 0$ and $\mathrm{P} 5$ rate. Different lowercases above the columns indicate significant difference $(P<0.05)$ among the three labile $C$ sources. Different uppercases indicate significant difference $(P<0.05)$ between $-\mathrm{IRB}$ and $+\mathrm{IRB}$ inoculations at the same $\mathrm{P}$ rate. Bars represent mean $+\mathrm{SE}(n=4)$. 


\subsection{Soil Fe dynamics}

Compared without IRB inoculation, the net rates of Fe reduction increased with IRB inoculation whether at $\mathrm{P} 0$ or $\mathrm{P} 5$. The net rates of Fe reduction had no difference among the three $\mathrm{C}$ input forms at the same IRB inoculation at a given $\mathrm{P}$ rate, except that of labile $\mathrm{C}$ added as a pulsed input, which was increased with IRB inoculation at P5 rate (Figure 3a).

Compared with that without IRB inoculation, $\mathrm{C} / \mathrm{A}$ extractable $\mathrm{Fe}(\mathrm{II})$ with IRB inoculation increased at both $\mathrm{P}$ rates. $\mathrm{C} / \mathrm{A}$ extractable $\mathrm{Fe}(\mathrm{II})$ had no difference among the three $\mathrm{C}$ input forms without IRB inoculation at a given $P$ rate. However, when inoculated with IRB, labile $\mathrm{C}$ added as a pulsed input increased the $\mathrm{C} / \mathrm{A}$ extractable $\mathrm{Fe}(\mathrm{II})$ whether at $\mathrm{P} 0$ or $\mathrm{P} 5$ rate. $\mathrm{At} \mathrm{P} 0$ rate, the $\mathrm{C} / \mathrm{A}$ extractable $\mathrm{Fe}(\mathrm{II})$ had no difference between labile $\mathrm{C}$ added as a single dose and no labile $\mathrm{C}$ input, but that of labile $\mathrm{C}$ added as a single dose was greater than that of no labile $\mathrm{C}$ input at $\mathrm{P} 5$ rate (Figure 3b).
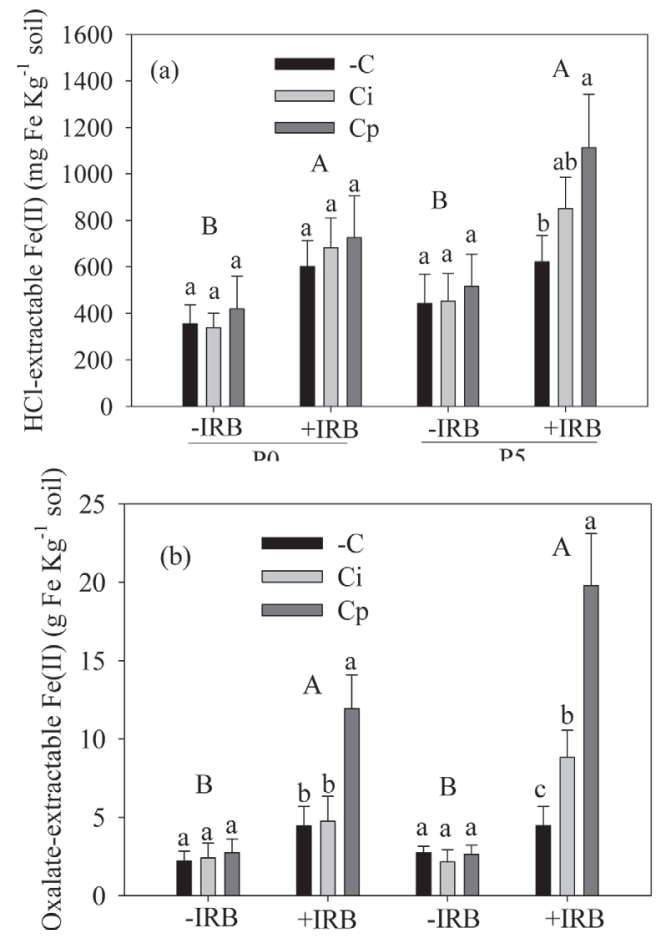

Figure 3. Effect of labile $\mathrm{C}$ source on $\mathrm{Fe}(\mathrm{II})$ production (a) and oxalate-extractable $\mathrm{Fe}$ (b) in hyphosphere soil of mycorrhizal plants inoculated without IRB (-IRB) and with IRB (+IRB) at P0 and P5. Different lowercases above the columns indicate significant difference $(P<0.05)$ among the three labile C sources. Different uppercases indicate significant difference $(P<0.05)$ between - IRB and + IRB inoculations at the same P rate. Bars represent mean $+\mathrm{SE}(n=4)$.

\section{5. $M B C$ and glomalin content}


Compared without IRB inoculation, IRB inoculation increased $\mathrm{MBC}$ content at both $\mathrm{P}$ rates $(\mathrm{p}<0.05)$. MBC content had no difference among the three labile $\mathrm{C}$ input forms at $\mathrm{P} 0$ rate whether with or without IRB inoculation. However, at $\mathrm{P} 5$ rate, the labile $\mathrm{C}$ input forms increased the $\mathrm{MBC}$ content compared without labile $\mathrm{C}$ input with IRB inoculation $(p<0.05)$. The increase rates of $\mathrm{MBC}$ among the three labile $\mathrm{C}$ input forms were from $33.3 \%$ to $68.4 \%$; without IRB inoculation, the increase rates of $\mathrm{MBC}$ among the three labile $\mathrm{C}$ input forms were from $62.1 \%$ to $58.1 \%$ (Table 2 ).
Whether at $\mathrm{P} 0$ or $\mathrm{P} 5$ rate, glomalin content had no significant differences among the three labile $\mathrm{C}$ input forms without IRB inoculation. However, when inoculated with IRB, soil glomalin content was highest with labile $\mathrm{C}$ added as a pulsed input, higher with labile $\mathrm{C}$ added as a single dose, and lowest without labile $\mathrm{C}$ input (Table 2 ). The increase rates of glomalin among the three labile $\mathrm{C}$ input forms were from $58.2 \%$ to $181.7 \%$ for $\mathrm{P} 0$ rate and from $73.3 \%$ to $375.4 \%$ for $\mathrm{P} 5$ rate.

Table 2. Effect of labile $C$ source on microbial biomass $C(M B C)$ and glomalin in hyphosphere soil of mycorrhizal plants inoculated without IRB (-IRB) and with IRB (+IRB) at P0 and P5. +IRB is the soil with IRB; -IRB is the soil without IRB; AM is the soil with mycorrhizae; P0 and P5 are two inorganic $\mathrm{P}$ rates with 0 or $5 \mathrm{mg} \mathrm{P} \mathrm{kg}{ }^{-1}$ soil as $\mathrm{KH}_{2} \mathrm{PO}_{4}$; -C was without additional $\mathrm{C}$ source; $\mathrm{Ci}$ was $24 \mathrm{mM}$ sodium acetate added at a rate of $23.04 \mathrm{mg} \mathrm{C}$ as a single dose; and $\mathrm{Cp}$ was as a pulsed input in four installments on days $0,10,17,24$, and 34 in hyphal compartments.

\begin{tabular}{|c|c|c|c|c|c|}
\hline \multirow[t]{2}{*}{ Inoculation } & \multirow[t]{2}{*}{ Labile C levels } & \multicolumn{2}{|c|}{$\begin{array}{c}\text { Microbial biomasses } \mathrm{C} \\
\left(\mathrm{mg} \mathrm{g}^{-1} \text { dry soil }\right)\end{array}$} & \multicolumn{2}{|c|}{$\begin{array}{c}\text { Glomalin } \\
\text { (mg g }{ }^{-1} \text { dry soil) }\end{array}$} \\
\hline & & $\mathrm{P} 0$ & P5 & $\mathrm{P} 0$ & P5 \\
\hline \multirow{3}{*}{$-I R B$} & $-\mathrm{C}$ & $7.23 \pm 1.13 \mathrm{a}^{1} B^{4}$ & $8.89 \pm 1.86 \mathrm{~b} A$ & $1.22 \pm 0.21 \mathrm{a} A$ & $1.80 \pm 0.22 \mathrm{a} A$ \\
\hline & $\mathrm{Ci}$ & $7.78 \pm 1.86 \mathrm{a} B$ & $9.38 \pm 2.42 \mathrm{~b} B$ & $1.56 \pm 0.39 \mathrm{a} B$ & $1.92 \pm 0.28 \mathrm{a} B$ \\
\hline & $\mathrm{Cp}$ & $9.81 \pm 2.12 \mathrm{a} B$ & $17.35 \pm 4.12 \mathrm{a} B$ & $1.53 \pm 0.41 \mathrm{a} B$ & $2.44 \pm 0.42 \mathrm{a} B$ \\
\hline \multicolumn{2}{|c|}{ Mean $^{2}$} & $8.67 \pm 1.84 \mathrm{~B}^{3}$ & $13.85 \pm 2.83 \mathrm{~B}$ & $1.47 \pm 0.33 \mathrm{~B}$ & $2.11 \pm 0.31 \mathrm{~B}$ \\
\hline & $-\mathrm{C}$ & $9.54 \pm 3.24 \mathrm{c} A$ & $9.41 \pm 5.80 \mathrm{c} A$ & $1.83 \pm 0.46 \mathrm{c} A$ & $2.12 \pm 0.43 \mathrm{c} A$ \\
\hline \multirow[t]{3}{*}{$+\mathrm{IRB}$} & $\mathrm{Ci}$ & $12.21 \pm 3.35 \mathrm{~b} A$ & $41.46 \pm 7.27 \mathrm{~b} A$ & $2.70 \pm 0.51 \mathrm{~b} A$ & $7.60 \pm 0.93 \mathrm{~b} A$ \\
\hline & $\mathrm{Cp}$ & $18.52 \pm 4.27 \mathrm{a} A$ & $62.94 \pm 10.42 \mathrm{a} A$ & $4.31 \pm 0.68 \mathrm{a} A$ & $11.60 \pm 1.11 \mathrm{a} A$ \\
\hline & Mean & $14.73 \pm 3.75 \mathrm{~A}$ & $51.48 \pm 10.85 \mathrm{~A}$ & $2.97 \pm 0.52 \mathrm{~A}$ & $7.47 \pm 3.23 \mathrm{~A}$ \\
\hline \multicolumn{6}{|c|}{ ANOVA (F values) } \\
\hline & B level & $14.12 * *$ & $18.12 * *$ & $15.38 * *$ & $18.36^{*}$ \\
\hline Labile & C level (C) & $12.45^{*}$ & $16.24 * *$ & $35.36 *$ & $24.73 * *$ \\
\hline & $\mathrm{RB} \times \mathrm{C}$ & $13.27 * *$ & $19.96 * * *$ & $17.26^{*}$ & $11.67 * *$ \\
\hline
\end{tabular}

Notes: Data are the means of four replicates \pm SEs. * denotes significant difference at $P=0.05, * *$ denotes significant difference at $P=0.01, * * *$ denotes significant difference at $P=0.001$, and NS denotes no significant difference. Data represent $\mathrm{F}$ values. ${ }^{1}$ Within each column, values with different letters are significantly different at the $P=0.05$ level. Across all labile C levels. ${ }^{2}$ Mean value for IRB level. ${ }^{3}$ Mean values with different capital letters are significantly different at the $P=0.05$ level between IRB levels. ${ }^{4}$ Values marked with different italic capital letters representsignificant difference at the $P=0.05$ level between $-\mathrm{IRB}$ and $+\mathrm{IRB}$ at a given $\mathrm{P}$ rate. 


\section{Discussion}

\subsection{IRB and FM interaction}

The interaction among microbial organisms influences each other not only on the development of colonization, but also on $\mathrm{P}$ acquisition and resource competition (Artursson et al. 2006; Arriagada et al. 2012; Tanwar et al. 2013). In the present study, mycorrhizal colonization and hyphal length density were higher when IRB was inoculated in the hyphosphere of the mycorrhizal plants (Table 1). This finding suggests that IRB can stimulate mycorrhizal colonization and positively affect $\mathrm{P}$ uptake from Fe-P when $\mathrm{P}$ was supplied (Figure1). At P0 rate, mycorrhizal colonization and hyphal length density had no difference among the three labile $\mathrm{C}$ inputs. However, at P5 rate, IRB mediated by labile $\mathrm{C}$ added as a pulsed input improved mycorrhizal colonization and hyphal length density, suggesting a remarkably positive relationship between FM and IRB and exogenous $\mathrm{P}$ rate input to improve the function of induced IRB.

Van Aarle et al. reported an increase of microbial biomass and bacterial activity in the presence of FM hyphae in limestone soil (van Aarle et al. 2003). In the present study, soil MBC was related with the labile $\mathrm{C}$ input forms at $\mathrm{P} 5$ rate. At $\mathrm{P} 5$ rate, soil MBC/MBP when labile $\mathrm{C}$ was added as a pulsed input was significantly higher than when labile $\mathrm{C}$ was added as a single dose (Table 2; Figure 2c). This may be attributed to the increase of soil MBC regulated by FM, which released more exudates containing energy-rich organic $\mathrm{C}$ compounds for the growth of IRB. Glomalin increased by adding labile $\mathrm{C}$ as a pulsed input when IRB exited (Table 2), possibly benefiting the growth of $M$. sativa by increasing MBP (Figure 2c; Table 1). The microbial biomass also contained a higher proportion of fungi, and the carbon produced by FM (Bronick and Lal 2005), possibly improve reductively dissolving Fe(III) (hydr) oxides by IRB. The labile C input forms might also regulate IRB with the rates of $\mathrm{Fe}$ (III) reduction, which significantly influenced phosphate desorption and the turnover of MBP.

\subsection{IRB and FM interaction on plant $P$ uptake by exogenous application of labile C input}

Bacteria can improve $\mathrm{P}$ utilization driven by microbial $\mathrm{C}$ acquisition from which plants potentially benefit (Spohn and Kuzyakov 2013; Schoebitz et al. 2013). In wet tropical ecosystems, Fe, P, and C cycles are tightly linked through oxidation and reduction dynamics (Liptzin and Silver 2009). In the present study, the release of Fe-P is closely linked to the redox processes of $\mathrm{Fe}$ oxide by IRB, which need more labile C (Figs. 2 and 3). Carbon can regulate the ratio of $\mathrm{C}: \mathrm{P}$ (Wu et al. 2007). Perhaps the presence of AM fungi provided substrates to IRB, which consume the complex organic material in the hyphosphere soil. Consequently, IRB can enhance the activation of Fe-P, thus positively affecting the links between AM fungi and plant roots (Zhang et al. 2013). In the present study, a remarkably positive relationship between exogenous application of labile $\mathrm{C}$ input and plant $\mathrm{P}$ content indicated that exogenous application of labile $\mathrm{C}$ added as a pulsed input can enhance plant $\mathrm{P}$ uptake at $\mathrm{P} 0$ rate. However, at $\mathrm{P} 5$ rate, exogenous application of labile $\mathrm{C}$ improved plant $\mathrm{P}$ uptake (Fig. 1). Labile $\mathrm{C}$ input 
forms can regulate the ratio of $\mathrm{C}: \mathrm{P}$ in soil, which could regulate IRB and FM interaction.

Aside from $\mathrm{C}, \mathrm{P}$ can regulate the ratio of $\mathrm{C}: \mathrm{P}$ and may therefore influence the plant-bacteria relationship. Previous studies mainly focused on the direct function of inorganic $\mathrm{P}$ on plant nutrition (Bittman et al. 2006); the indirect effects on bacterial activity and MBP content were not considered. The present experiment aimed to enhance the release of Fe-bound $\mathrm{P}$ by adding a small amount of inorganic $\mathrm{P}$, which can decrease soil $\mathrm{C}: \mathrm{P}$ and thus regulate the competition between plant and bacteria. In soil with low available $\mathrm{P}$ content, bacteria can compete for $\mathrm{P}$ with plants and inhabit root uptake although they can release Fe-bound $\mathrm{P}$ (Figure1). However, adding a small amount of inorganic $\mathrm{P}$ to the soil decreased the ratio of $\mathrm{C}: \mathrm{P}$ and eliminated the competition. As a result, bacteria mobilized more Po than it immobilized and increased plant $\mathrm{P}$ uptake by labile $\mathrm{C}$ added as a pulsed input (Figure 1; Figure 2a).

\subsection{Fe reduction by IRB with exogenous application of labile $C$ input}

Fe-P is a form of inorganic $\mathrm{P}$ in subtropical soil, representing a large potential $\mathrm{P}$ for plants. $\mathrm{Fe}$ reduction related to the potential to release Febound $\mathrm{P}$ has been well documented in anaerobic environments, but the redox dynamics of $\mathrm{Fe}$ may more significantly affect $\mathrm{P}$ cycling and biological activity in agricultural ecosystems. The rates of Fe reduction may be affected by the concentration and phase of oxidized secondary minerals present (Liptzin and Silver 2009). For instance, poor crystalline phases of Fe(III), such as ferrihydrite, are more reducible than phases with higher crystallinity (Roden and Urrutia 2002). In the present study, compared with those without IRB inoculation, the net rates of $\mathrm{Fe}$ reduction increased with inoculation with IRB whether at $\mathrm{P} 0$ or $\mathrm{P} 5$ rate (Figure $2 \mathrm{a}$ ). As a biogeochemical redox agent, IRB can increase the mineralization of soil organic matter and enhance nutrient availability, especially $\mathrm{P}$ from Fe-P in tropical and subtropical soil. Several studies have also demonstrated increases in soluble $\mathrm{P}$ in association with $\mathrm{Fe}(\mathrm{II})$ production with and without the addition of simple $\mathrm{C}$ substrates or synthetic electron shuttle compounds (Chacon et al. 2006). In the present study, the net rates of Fe reduction had no difference among the three $\mathrm{C}$ input forms without IRB inoculation at a given $P$ rate, except that labile $C$ added as a pulsed input increased the net rates of $\mathrm{Fe}$ reduction with IRB inoculation at P5 rate (Figure 2a), supporting previous findings that the addition of electron shuttles may increase the reducibility of Fe phases of higher crystallinity (Rakshit et al. 2009).

Fe reduction appears to be stimulated by the addition of labile $\mathrm{C}$ compounds, such as acetate (Chacon et al. 2006). In the present study, compared with that in no IRB inoculation, C/A extractable $\mathrm{Fe}$ (II) increased with the inoculation of IRB whether at P0 or P5. C/A extractable $\mathrm{Fe}$ (II) had no difference among the three $\mathrm{C}$ input forms without IRB inoculation at a given $\mathrm{P}$ rate (Figure 2b). Compared with other labile $\mathrm{C}$ input forms, labile $\mathrm{C}$ added as a pulsed input increased $\mathrm{C} / \mathrm{A}$ extractable $\mathrm{Fe}(\mathrm{II})$ with $\mathrm{IRB}$ inoculation whether at $\mathrm{P} 0$ or $\mathrm{P} 5$ rate. At $\mathrm{P} 0$ rate, $\mathrm{C} / \mathrm{A}$ extractable $\mathrm{Fe}(\mathrm{II})$ had no difference between labile $\mathrm{C}$ added as a single dose and no labile $\mathrm{C}$ input, but that of labile $\mathrm{C}$ added as a single dose 
was higher than that of no labile $\mathrm{C}$ input at P5 rate (Figure 2b), suggesting that the presence of organic molecules that can shuttle electrons from organisms to solid phase Fe minerals affects $\mathrm{Fe}$ reduction rates.

In conclusion, the present study provided a reliable evidence that exogenous application of labile $\mathrm{C}$ added as a pulsed input enhanced the ability of IRB to improve Fe reduction and increased the utilization of Fe-P by mycorrhizal plants in subtropical soil.

\section{Acknowledgments}

The study was supported by the State Nature Science Foundation of China (31201693), the Nature Science Foundation of Guangdong province (S2012040006938) and the Scientific Research Foundation of Guangdong Academy of Sciences (rcjj201202; qnjjsq201102).

\section{References}

Adesemoye, AO., Kloepper, J.W. 2009. Plantmicrobes interactions in enhanced fertilizer-use efficiency. Appl. Microbiol. Biot. 85, 1-12.

Amato, M., Ladd, J. 1988. Assay for microbial biomass based on ninhydrin-reactive nitrogen in extracts of fumigated soils. Soil Biol. Biochem. 20, 107-114.

Artursson, V, Finlay, R.D, Jansson, J.K. 2006. Interactions between arbuscular mycorrhizal fungi and bacteria and their potential for stimulating plant growth. Environ Microbiol. 8, 1-10.

Arriagada, C., Manquel, D., Cornejo, P., Soto, J., Sampedro, I., Ocampo, J. 2012. Effects of the coinoculation with saprobe and mycorrhizal fungi on Vaccinium corymbosum growth and some soil enzymatic activities. J. Soil Sci. Plant Nut. 12 (2): 283-294.

Bago, B., Pfeffer, P.E., Zipfel, W., Lammers, P., Shachar-Hill, Y. 2002. Tracking metabolism and imaging transport in arbuscular mycorrhizal fungi. Metabolism and transport in AM fungi. Plant Soil. 244, 189-197.

Baldwin, D.S., Mitchell, A. 2000. The effects of drying and re-flooding on the sediment and soil nutrient dynamics of lowland river-floodplain systems: a synthesis. Regulated Rivers: Research \& Management. 16, 457-467.

Bittman, S., Kowalenko, C.G., Hunt, D.E., Forge, T.A., Wu, X. 2006. Starter phosphorus and broadcast nutrients on corn with contrasting colonization by mycorrhizae. Agron. J. 98, 394401.

Bronick, C., Lal R. 2005. Soil structure and management: a review. Geoderma. 124, 3-22.

Brookes. P., Landman A., Pruden, G., Jenkinson, D. 1985. Chloroform fumigation and the release of soil nitrogen: a rapid direct extraction method to measure microbial biomass nitrogen in soil. Soil Bio. Biochem. 17, 837-842.

Chacon, N., Silver, W.L., Dubinsky, E.A., Cusack, D.F. 2006. Iron reduction and soil phosphorus solubilization in humid tropical forests soils: the roles of labile carbon pools and an electron shuttle compound. Biogeochemistry. 78, 67-84.

Chao, T., Zhou, L. 1983. Extraction techniques for selective dissolution of amorphous iron oxides from soils and sediments. Soil Sci. Soc. Am. J. 47, 225-232.

Ivanov, V., Stabnikov, V., Zhuang, W., Tay, J., Tay, S. 2005. Phosphate removal from the returned liquor of municipal wastewater treatment plant using iron reducing bacteria. J. Appl. Microbiol. 98, 1152-1161. 
Liptzin, D., Silver, W.L. 2009. Effects of carbon additions on iron reduction and phosphorus availability in a humid tropical forest soil. Soil Biol Biochem. 41, 1696-1702.

Lovley, D.R., Holmes, D.E, Nevin, K.P. 2004. Dissimilatory Fe (III) and Mn (IV) reduction. Adv. Microb. Physiol. 49, 219-286.

Lovley, D.R., Phillips, E.J. 1987. Competitive mechanisms for inhibition of sulfate reduction and methane production in the zone of ferric iron reduction in sediments. Appl. Environ. Microb. $53,2636-2641$.

McKeague, J., Day, J.H. 1966. Dithionite-and oxalate-extractable $\mathrm{Fe}$ and $\mathrm{Al}$ as aids in differentiating various classes of soils. Can. J. Soil Sci. 46, 13-22.

Murphy, J., Riley, J. 1962. A modified single solution method for the determination of phosphate in natural waters. Anal. Chim. Acta. 27, 31-36.

Minaxi, Saxena, J., Chandra, S., Nain, L. 2013. Synergistic effect of phosphate solubilizing rhizobacteria and arbuscular mycorrhiza on growth and yield of wheat plants. J. Soil Sci. Plant Nut. 13 (2): 511-525.

Newman, E. 1966. A method of estimating the total length of root in a sample. J. Appl. Ecol. 139-145.

Rakshit, S., Uchimiya, M., Sposito, G. 2009. Iron (III) bioreduction in soil in the presence of added humic substances. Soil Sci. Soc. Am. J. 73, 65-71.

Richardson, AE, Simpson, R.J. 2011. Soil microorganisms mediating phosphorus availability update on microbial phosphorus. Plant Physiol. 156, 989-996.

Roden, E.E., Urrutia, M.M. 2002. Influence of biogenic $\mathrm{Fe}$ (II) on bacterial crystalline $\mathrm{Fe}$ (III) oxide reduction. Geomicrobiol, J. 19, 209-251.
Schoebitz, M., Ceballos, C., Ciampi, L. 2013. Effect of immobilized phosphate solubilizing bacteria on wheat growth and phosphate uptake. J Soil Sci. Plant Nut. 13 (1): 1-10.

Sparling, G., Feltham, C., Reynolds, J., West, A., Singleton, P. 1990. Estimation of soil microbial c by a fumigation-extraction method: use on soils of high organic matter content, and a reassessment of the $k_{\text {ec-factor }}$. Soil Biol. Biochem. 22, 301-307.

Spohn, M., Kuzyakov, Y. 2013. Phosphorus mineralization can be driven by microbial need for carbon. Soil Biol. Biochem. 61, 69-75.

Szilas, C., Borggaard, O., Hansen, H., Rauer, J. 1998. Potential iron and phosphate mobilization during flooding of soil material. Water Air Soil Poll. 106, 97-109.

Tanwar, A., Aggarwal, A., Kadian, N., Gupta, A. 2013. Arbuscular mycorrhizal inoculation and super phosphate application influence plant growth and yield of Capsicum annuum. J. Soil Sci. Plant Nut. 13 (1): 55-66.

Toljande, J., Artursson, V., Paul, L.R., Jansson, Jk., Finlay, R.D. 2006. Attachment of different soil bacteria to arbuscular mycorrhizal fungal extraradical hyphae is determined by hyphal vitality and fungal species. FEMS Microbiol. Lett. 254, 34-40.

Trouvelot, A., Kough, J.L., Gianinazzi-Pearson, V. 1986. Mesure du taux de mycorhization VA d'un système radiculaire. Recherche de méthodes d' estimation ayant une signification fonctionnelle. In: Physiological and genetical aspects of mycorrhizae. Paris, France: INRA Press.

van Aarle, I.M., Söderström, B., Olsson, P.A. 2003. Growth and interactions of arbuscular mycorrhizal fungi in soils from limestone and acid rock habitats. Soil Biol. Biochem. 35, 1557-1564. 
Vance, E., Brookes, P., Jenkinson, D. 1987. An extraction method for measuring soil microbial biomass C. Soil Biol. Biochem. 19, 703-707.

Walkley, A. 1947. A critical examination of a rapid method for determining organic carbon in soilseffect of variations in digestion conditions and of inorganic soil constituents. Soil Sci. 63, 251-264.

Wu, J.S., Huang, M., Xiao, H.A., Su, Y.R., Tong, C.L., Huang, D.Y., Syers, J.K. 2007. Dynamics in microbial immobilization and transformations of phosphorus in highly weathered subtropical soil following organic amendments. Plant Soil. 290, 333-342.
Wright, S., Upadhyaya, A. 1998. A survey of soils for aggregate stability and glomalin, a glycoprotein produced by hyphae of arbuscular mycorrhizal fungi. Plant Soil. 198, 97-107.

Zhang, S.R., Wang, R.P., Zhang, L., Li, S.Y., Feng, G., Ding, X.D. 2014. Iron-reducing bacteria can enhance the activation and turnover of the Fe(III)fixed phosphorus for mycorrhizal plants. J. Plant Nut. Soil Sci. 177, 208-215. 
